\title{
Treaty framing and climate science: challenges in managing the risk of global warming
}

\section{William Leiss}

School of Policy Studies,

Queen's University,

Kingston, Canada

Email: leissw@queensu.ca

and

R. Samuel McLaughlin Centre for

Population Health Risk Assessment, University of Ottawa, Canada

\section{Michael G. Tyshenko}

Risk Sciences International,

Ottawa, Canada

Email: mtyshenko@risksciences.com

\section{Patricia Larkin*}

R. Samuel McLaughlin Centre for Population Health Risk Assessment, University of Ottawa, Canada

Email: plarkin@xplornet.com

*Corresponding author

\section{Daniel Krewski}

Risk Sciences International,

Ottawa, Canada

and

R. Samuel McLaughlin Centre for

Population Health Risk Assessment, University of Ottawa, Canada

Email: dkrewski@uottawa.ca

\begin{abstract}
In this article we confront the yawning gap between necessary GHG emission reduction targets set by climate scientists and the results of decades-long international treaty negotiations and meetings. We find that, 30 years after the treaty process commenced, this gap is still growing. The treaty process first tried a top-down approach, in the 1997 Kyoto Protocol, and later a bottom-up one, in the 2015 Paris Agreement, but so far the later results have proved no better than the earlier ones. We suggest, therefore, that a different approach should be implemented. We propose that the advanced economies should begin, as soon as possible, subsidising a massive program to promote
\end{abstract}


decarbonisation in the still developing economies by providing free of charge, a very extensive array of non-fossil-fuel technologies and facilities. At the end of this article we refer to a specific framework within which this mission could be carried out.

Keywords: environmental treaty law; Paris Agreement; climate forcing; climate science; greenhouse gas targets; risk; global warming.

Reference to this paper should be made as follows: Leiss, W., Tyshenko, M.G., Larkin, P. and Krewski, D. (2020) 'Treaty framing and climate science: challenges in managing the risk of global warming', Int. J. Global Environmental Issues, Vol. 19, Nos. 1/2/3, pp.273-293.

Biographical notes: William Leiss is a Fellow and the Past-President in 1999-2001 of the Royal Society of Canada and an officer in the Order of Canada. He is currently a Scientist at the McLaughlin Centre for Population Health Risk Assessment, University of Ottawa. From 1999 to 2004, he held the NSERC/SSHRC/Industry Research Chair in Risk Communication and Public Policy at the Haskayne School of Business, University of Calgary. From 1994 to 1999, he held the Eco-Research Chair in Environmental Policy at the Queen's University, Ontario. He is an author of Risk and Responsibility (1994), Mad Cows and Mother's Milk: The Perils of Poor Risk Communication (1997, 2004), in the Chamber of Risks: Understanding Risk Controversies (2001), all from McGill-Queen's University Press.

Michael G. Tyshenko is a risk analyst at Risk Sciences International, Ottawa, Canada. His academic background includes a PhD in Molecular Biology and a MPA in Public Administration. He completed his Post-doctoral training in Health Policy Studies and held the prestigious McLaughlin Chair in Science Health Policy at the Institute of Population Health, University of Ottawa. His research areas include pandemic planning, emerging zoonotic diseases, medical nanotechnology, health risk communication, and e-health initiatives.

Patricia Larkin's research in population health risk management is focused on structural and intermediary determinants of health and their interactions. Her special interests include minimising health risks of climate policy and decision-making affecting energy, carbon capture and storage, agriculture, and rural development. She contributes to the work of the McLaughlin Centre for Population Health Risk Assessment and the Institute for Science Society and Policy, both at the University of Ottawa. She is an active member of the Society for Risk Analysis, and serves on various boards of regional importance, including the Mississippi Rideau Source Protection Committee.

Daniel Krewski is a Professor in the School of Epidemiology and Public Health in the Faculty of Medicine at the University of Ottawa, where he also serves as the Scientific Director of the McLaughlin Centre for Population Health Risk Assessment. $\mathrm{He}$ is currently holds a Natural Sciences and Engineering Research Council of Canada Chair in Risk Science at Ottawa, and serves as the Chief Risk Scientist at Risk Sciences International, a Canadian company established in 2006 in partnership with the University of Ottawa (http://www.risksciences.com). His research interests include epidemiology, biostatistics, risk assessment and risk management. He is a Fellow of the Society for Risk Analysis the American, Statistical Association and a National Affiliate of the US National Academy of Sciences. 


\section{Introduction}

Around 1990 the nations of the world embarked on a sustained, collective effort to limit and reduce global greenhouse gas (GHG) emissions from anthropogenic sources, an effort which continues to this day through an international agreement ratified by 185 parties and in force since 2016. However, between 1990 and 2018 humanity's releases of carbon dioxide $\left(\mathrm{CO}_{2}\right)$, which accounts for about three-quarters of all GHG emissions, increased by $67 \%$ (EC, 2019). In fact, the growth rate of $\mathrm{CO}_{2}$ emissions is accelerating, having been substantially higher in the most recent decade (2010-2019) than it was in the two prior decades (NOAA, USA, 2019). Peters et al. (2019) sum up as follows: "The continued growth in global fossil $\mathrm{CO}_{2}$ emissions is taking place despite growing public and policy attention, five cycles of IPCC Assessment Reports and almost 30 years of international climate negotiations."

Global GHG emissions have three major components:

$1 \mathrm{CO}_{2}$, where combustion of fossil-fuels is the primary source

2 non- $\mathrm{CO}_{2}$ gases (methane $\left[\mathrm{CH}_{4}\right]$ and others)

3 a separate category for GHG emissions resulting from land-use and land-use change (such as in agriculture) and changes in the earth's forest cover [LULUCF (Houghton and Nassikas, 2017)].

Quantities are expressed in terms of either megatonnes (Mt) or gigatonnes (Gt). Emissions numbers for the second and third categories are normally converted into their equivalent in $\mathrm{CO}_{2}$ (abbreviated $\mathrm{CO}_{2}$ eq). Olivier and Peters (2018) write: " $\mathrm{CO}_{2}$ emissions are the largest source of GHG emissions, with a share of about $73 \%$, followed by $\mathrm{CH}_{4}$ $(18 \%)$, nitrous oxide $\left(\mathrm{N}_{2} \mathrm{O}\right)(6 \%)$, and fluorinated gases $(3 \%)$." The emissions numbers cited in this paper will vary depending on whether they are depicting GHG emissions from all sources, or only fossil-fuel emissions $\left(E_{F F}\right)$. The latest full estimate for global emissions is for 2018 (Friedlingstein et al., 2019; cf. Jackson et al., 2019; Olivier and Peters, 2019):

"In 2018, the largest absolute contributions to global $\mathrm{CO}_{2}$ emissions were from China (28\%), the USA (15\%), the EU (28 member states) $(9 \%)$, and India (7\%). These four regions account for $59 \%$ of global $\mathrm{CO}_{2}$ emissions, while the rest of the world contributed $41 \%$, which includes aviation and marine bunker fuels (3.4\% of the total). Growth rates for these countries from 2017 to 2018 were $2.3 \%$ (China), $2.8 \%$ (USA), $-2.1 \%$ (EU-28), and $8.0 \%$ (India), with $1.8 \%$ for the rest of the world."

Friedlingstein et al. (2019) state that the record up to 2018 "brings the total $\mathrm{CO}_{2}$ emissions from fossil fuel plus land use change $\left(E_{F F}+E_{L U C}\right)$ to $11.5 \pm 0.9 \mathrm{GtC}$ $\left(42.5 \pm 3.3 \mathrm{GtCO}_{2}\right)$." Early in 2017, when emissions data for 2016 had been finalised, it looked as if this powerful driver of climate change had finally peaked. For 2016 was the third consecutive year in which global emissions had remained basically unchanged, leading to the possibility that the initial fundamental objective of climate change action plans, namely GHG stabilisation, had been secured. But this has not happened. Global GHG emissions began rising again, with increases of $1.3 \%$ in 2017 and $2.7 \%$ for 2018 , respectively, with an expected additional global rise of $+0.6 \%$ in 2019. Estimated national increases for 2019 over 2018 include China (2.6\%) and India (at 1.8\%), with decreases (of $-1.7 \%$ ) for the EU and the USA [Friedlingstein et al., (2019), 
Subsection 3.4.1]. Although the Coronavirus pandemic likely will depress earlier projections for rising emissions in 2020, at the time of writing it is unclear whether this event will have an impact on longer-term trends.

$\mathrm{CO}_{2}$ has an atmospheric lifetime between five and two hundred years (IPCC, 2001; Hansen et al., 2007). Accumulated emissions load ever more momentum into the climateforcing mechanism, as the climate system slowly seeks a new equilibrium state. The long lifetime of $\mathrm{CO}_{2}$ in the atmosphere means that emissions over the past century and even beyond, not only the recent emissions, are important. Although China is presently the largest source of current emissions, the highest cumulative contributors to global emissions are: USA (25\%), EU-28 (22\%), China (13\%), Russia (7\%), Japan (4\%), and India (3\%). Thus, as of 2017, the USA, the EU and Japan combined accounted for $51 \%$ of cumulative emissions (Global Carbon Project, 2018) [see also Ritchie and Roser (2020) 'cumulative $\mathrm{CO}_{2}$ emissions by World Region', which is an interactive graphic that depicts estimated shares of historical emissions by year from 1751 to 2017 (Mathews et al., 2018; Rocha et al., 2015)].

As current emissions continue to increase, the prospects for effective global countervailing action appear to be receding further and further into the future. This decades-old mismatch between ever-rising emissions, on the one hand, and lack of progress in implementing international treaty-determined action plans, on the other, represents a significant dilemma in the climate change issue. We characterise this dilemma as the tension between climate forcing and treaty forcing.

Climate forcing - also known as radiative forcing - can be defined as an imposed perturbation of Earth's energy balance (NAP, 2001; NOAA, USA, 2019). Energy flows in from the sun, much of it in the visible wavelengths, and back out again as long-wave infrared (heat) radiation. An increase in the luminosity of the sun, for example, is a positive forcing that tends to make earth warmer. A very large volcanic eruption, on the other hand, can increase the aerosols (fine particles) in the lower stratosphere at altitudes of 16-20 kilometres that reflect sunlight to space and thus reduce the amount of solar energy reaching earth's surface. These examples are natural forcings. Anthropogenic forcings result from, among other sources, the gases and aerosols produced by burning fossil fuels and alterations of earth's surface from various changes in land use, such as the conversion of forests into agricultural land. Those gases that absorb infrared radiation - the so-called 'greenhouse' gases - tend to prevent this heat radiation from escaping to space, leading eventually to a warming of Earth's surface. The now well-documented human-induced forcings underlie the ongoing concerns about climate change (IPCC, 2014a).

International environmental treaty law processes seek voluntary acceptance by nations of mutual obligations that govern practices which have an appreciable impact on global conditions. In the context of climate change, we define treaty forcing as the variety of processes whereby all or some of the nations which emit GHGs use an international treaty framework to determine how and when emissions reductions will occur. The major steps have been: the UNFCCC (1992) and its following steps, the 1997 Kyoto Protocol (UNFCCC, 2008, 2019a) and its Doha Amendment (UNFCCC, 2012), and the Paris Agreement (UNFCCC, 2015a). It was Article 2 of the UNFCCC which characterised the ultimate objective of global action as "stabilization of greenhouse gas concentrations in the atmosphere at a level that would prevent dangerous anthropogenic interference with the climate system." In attempting to meet this objective, subsequent developments have 
moved from a largely top-down strategy (Kyoto and Doha) to a bottom-up one (Paris), the last of which is more inclusive than its predecessors.

It is important to recall that there are other contributors to climate forcing that are not covered in the international treaties on climate change. These contributors include land-use and land-use-change, already mentioned, and black carbon, which according to some estimates vies with methane as the second-largest factor in climate forcing after carbon dioxide. Black carbon, and to a lesser extent brown carbon, are particulate emissions, not gases, which are generated by the incomplete combustion of fossil fuels and biomass, and which have a major impact on human health as well as on climate change. Advance industrial economies have taken important steps to reduce emissions of black carbon and are committed to achieving further reductions (CCAC, 2018).

\subsection{The Paris Agreement of 2015}

The 2015 Paris Climate Agreement seeks to enhance the eventual implementation of the UNFCCC objectives and to strengthen the global response to the threat of climate change by "[h]olding increases in the global average temperature to well below $2^{\circ} \mathrm{C}$ above pre-industrial levels and pursuing efforts to limit the temperature increase to $1.5^{\circ} \mathrm{C}$ above pre-industrial levels, recognizing that this would significantly reduce the risks and impacts of climate change" (Article 2.1). To achieve these temperature goals, the Paris Agreement states (Article 4.1) that Parties will "aim to reach global peaking of greenhouse gas emissions as soon as possible, recognizing that peaking will take longer for developing country Parties, and to undertake rapid reductions thereafter in accordance with best available science, so as to achieve a balance between anthropogenic emissions by sources and removals by sinks of greenhouse gases in the second half of this century" (Bodansky, 2016; Doelle, 2016, 2017). Unlike the Kyoto protocol, the Paris Agreement encourages the actions of non-state and subnational actors (Hsu et al., 2019).

At the core of the Paris Agreement are 'nationally determined contributions' (NDCs, also referred to as INDCs, intended nationally determined contributions), which are submissions by the parties representing their voluntary and individually-framed targets for GHG emissions reductions (Doelle, 2019). However, even as the Paris Agreement was being negotiated and adopted at the 21 st Conference of the Parties (COP) meeting, the UNFCCC Secretariat was circulating a "synthesis report on the aggregate effect of the intended nationally determined contributions", which warned: "the estimated aggregate annual global emission levels resulting from the implementation of the INDCs do not fall within least-cost $2^{\circ} \mathrm{C}$ scenarios by 2025 and $2030 \ldots$ Therefore, much greater emission reductions effort than those associated with the INDCs will be required in the period after 2025 and 2030 to hold the temperature rise below $2^{\circ} \mathrm{C}$ above pre-industrial levels" (UNFCCC, 2015b).

\section{What are the prospects for treaty success?}

During the long period of climate-change negotiations, the gap between treaty-determined targets and actual global performance has steadily widened (Figure 1). 
Figure 1 Comparison of five international $\mathrm{CO}_{2}$ emissions reductions targets with actual and estimated global $\mathrm{CO}_{2}$ emissions from 1988 to 2030 (see online version for colours)

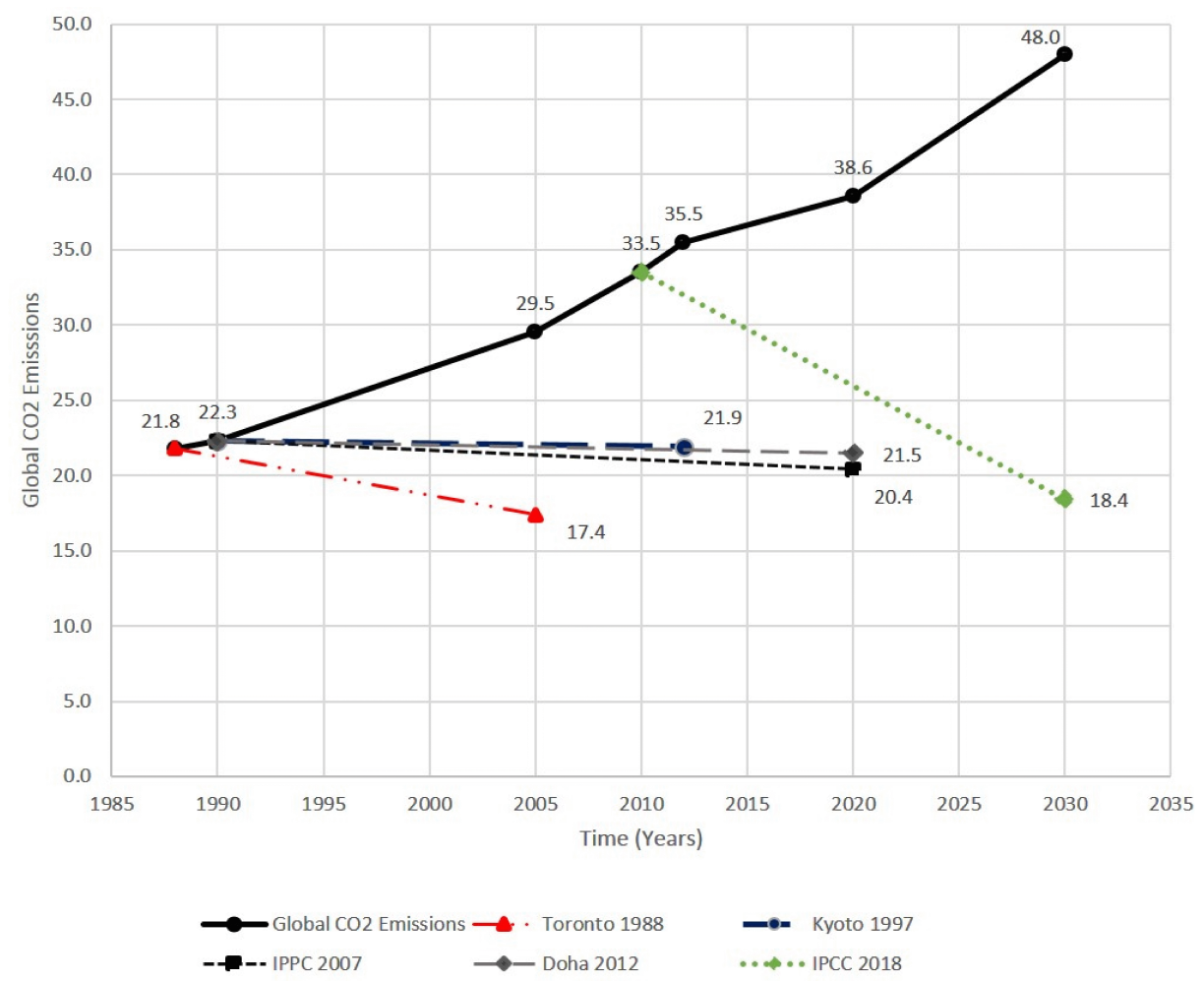

Notes: 1 Emissions data 1988 to 2012: US Department of Energy CDIAC (2019) (converted from carbon to $\mathrm{CO}_{2}$ ).

2 Emissions estimates 2020 and 2030: 2018 plus 2\%/year.

3 'International Conference on the Changing Atmosphere', Toronto, Canada (Toronto Conference, 1988).

4 The Kyoto Protocol targets applied only to 39 developed countries (Annex 1). It covered approximately one-third of global emissions, and the calculation in Figure 6 of the 2012 target is adjusted accordingly $(-5 \% \times 33 \%)$. It should be noted that the Annex 1 countries (minus the USA) met and substantially exceeded their Kyoto targets (Olivier, 2011).

5 IPCC Fourth Assessment Report: Climate Change 2007, Mitigation of Climate Change, p.776, Annex 1 countries, $-25 \%$ to $-40 \%$ below 1990 levels by 2020 , assuming $-25 \%$ and adjusted as per note $2 .{ }^{*} \mathrm{~T}$ reflects this limited application of the emissions reduction target figure.

6 The Doha Amendment to the Kyoto Protocol, which has not come into force, represents an additional commitment (beyond Kyoto) of the industrialised countries and 'economies in transition', but covers only $11 \%$ of global emissions. ${ }^{*} \mathrm{~T}$ reflects this limited application of the emissions reduction target figure.

7 For GHG emissions (in terms of $\mathrm{GtCO}_{2} \mathrm{eq}$ ), IPCC (2018) (SR-15) has targets of $-45 \%$ of 2010 levels by 2030 (to limit warming to $\left.1.5^{\circ}\right)$ and $-25 \%(2010$ levels) by 2030 for a limit of $2.0^{\circ}$. The UNFCCC Talanoa 2018 target is $-50 \%$ by 2030 . 
At the same time, expert consensus documents, especially those issued by the Intergovernmental Panel on Climate Change (IPCC), have been seeking to be more and more precise on what targets are needed in order to avoid exceeding the thresholds of $+1.5^{\circ} \mathrm{C}$ and $+2^{\circ} \mathrm{C}$ warming. The IPCC's $(2018$, p.14) most recent document, the Special Report (SR-15), includes both warming projections and emissions reductions targets to keep warming below these two levels: "in model pathways with no or limited overshoot of $1.5^{\circ} \mathrm{C}$, global net anthropogenic $\mathrm{CO}_{2}$ emissions decline by about $45 \%$ from 2010 levels by 2030 (40-60\% interquartile range), reaching net zero around 2050 (2045-2055 interquartile range). For limiting global warming to below $2{ }^{\circ} \mathrm{C} \mathrm{CO}_{2}$ emissions are projected to decline by about $25 \%$ by 2030 in most pathways (10-30\% interquartile range) and reach net zero around 2070 (2065-2080 interquartile range)." For discussions on these targets see Goodwin et al. (2018a, 2018b), Hausfather et al. (2020), Jackson et al. (2017, 2018, 2019), Mengis et al. (2018), Smith et al. (2018), Xu and Ramanathan (2017) and $\mathrm{Xu}$ et al. (2018). A number of studies [especially the collection (Mitchell et al., 2018)] argue that the expected impacts at $+2.0^{\circ} \mathrm{C}$ are substantially greater than those at $+1.5^{\circ} \mathrm{C}$.

The risk that both of these temperature targets may be exceeded now points explicitly to the need for arriving at the point of net-negative global emissions, continuing indefinitely into the future, even after net zero has been attained. Net-negative means that carbon-dioxide removal technologies, in addition to emissions reductions strategies, must be deployed in order to lower atmosphere concentrations of $\mathrm{CO}_{2}$ and lower global average temperatures (Fuss et al., 2014; Fawzy et al., 2020; Forster et al., 2020).

And yet, with each passing year, actual attainment of these goals can appear to be more and more unrealistic. The scientific analyses of climate forcing routinely refer to the urgent need to use further treaty framing to ensure that emissions reductions targets may be met, but they also routinely neglect to examine the efficacy of the treaty process more generally. A look at this larger record shows the inherent difficulty, and frequent failures, in international treaty negotiations which attempt to deal with the combined political and environmental impacts of global issues. The record of these failures and limitations since the middle of the 20th century includes the Chemical Weapons Convention, the Biological Weapons Convention, the many nuclear weapons treaties (SALT, START, and their successors), the International Convention on the Regulation of Whaling, and others. (The sole exception is the Montreal Protocol on Substances that Deplete the Ozone Layer. In the supplementary information to this paper, available online, we provide full details of this and related issues. See Harvard Dataverse: https://doi.org/10.7910/DVN/ 2SUI27). This reality leads us to suggest, at the end of this paper, that starting in 2020 nations should choose a targeted strategy for future GHG emissions reductions which had been situated within the Paris Agreement in 2015, but which has not yet been implemented. 


\title{
3 Grappling with $1.5^{\circ} \mathrm{C}$ warming
}

As discussed earlier, in the context of the 2015 Paris Agreement both the target of ideally limiting warming to $1.5^{\circ} \mathrm{C}$ above pre-industrial levels, and a warning that the announced, self-imposed limits of the parties would not allow the target to be reached, had been put on record. In the aforementioned IPCC Special Report (SR-15), the earlier warning was now formulated in much more precise and stark terms [IPCC, (2018), p.D.1]:

\begin{abstract}
"Estimates of the global emissions outcome of current nationally stated mitigation ambitions as submitted under the Paris Agreement would lead to GHG emissions in 2030 of $52-58 \mathrm{GtCO}_{2}$ eq $\mathrm{yr}-1$ (medium confidence). Pathways reflecting these ambitions would not limit global warming to $1.5^{\circ} \mathrm{C}$, even if supplemented by very challenging increases in the scale and ambition of emissions reductions after 2030 (high confidence)."
\end{abstract}

This radical resetting for the climate-forcing timelines is, of course, directly relevant to the treaty-dependent provisions that will be required to deliver emissions reductions results on that basis. Recent projections point to 2030 as the time when $+1.5^{\circ} \mathrm{C}$ warming will be reached ( $\mathrm{Xu}$ et al., 2018). How difficult will it be to avoid this outcome? To assess this situation, the information assembled in Table 1 must be considered carefully.

The long-term emissions trend lines (1990-2018) for the six largest emitters, the countries or regions where annual $\mathrm{CO}_{2}$ emissions now exceed 1,000 Mt (1 Gt) annually, are: China, $+469 \%$; India, $+441 \%$; Japan, $+5 \%$; USA, $+4 \%$; EU-28, $-21.5 \%$; Russian Federation, $-26 \%$; World, $+67.4 \%$ (EC, 2019, Figure 1). The substantial decrease for the Russian Federation is related to the economic consequences resulting from the collapse of the Soviet Union. As indicated in Table 2, the most likely future scenarios for the period 2018-2030 are that three (USA, EU-28, and Japan) will show decreases and the other three (China, India, and Russia) will show increases. Large increases for China and India, taken together, are likely to exceed the total of any others' decreases by a wide margin, resulting in a significant net gain in global emissions as at 2030. We calculate some rough projections for the countries among the top $6 \mathrm{CO}_{2}$ emitters, starting with China and India (Table 2).

As seen in Table 1, the second set of ten countries is collectively responsible for around $14.5 \%$ of global emissions. Among them, only three on the list (South Korea, Canada, and Australia) are fully-developed modern economies, which might show some relatively minor future reductions, but this is by no means certain: Canada, for example, may not meet either its announced interim 2020 target or its 2030 target (Canada, 2017, 2019; CAT, 2019a; Saxifrage, 2019). One can therefore reasonably project a net increase for the second set of ten countries as a whole to counteract the substantial $25 \%$ net increase among the top 6. Although all countries have responsibility to limit GHG emissions, future decisions by China and India in this regard will be of paramount importance in achieving the global warming target. 
Table 1 INDCs for the top 16 GHG emitters (Paris Agreement)

\begin{tabular}{|c|c|c|c|c|c|}
\hline$A$ & $\begin{array}{l}B: \text { country } \\
\text { or region }\end{array}$ & $\begin{array}{c}\text { C: } 2018 \mathrm{CO}_{2} \\
\text { emissions (Mt) }\end{array}$ & $\begin{array}{l}\text { D: } 2018 \\
\text { increase }\end{array}$ & $\begin{array}{l}\text { E: emissions } \\
\text { per capita }(t)\end{array}$ & $F:$ first $N D C$ \\
\hline 1 & China & $11,256(29.7 \%)$ & $+1.5 \%$ & 7.95 & $\begin{array}{l}\text { Emissions peaking } \\
\text { 'around' } 2030\end{array}$ \\
\hline 2 & USA & $5,275(13.9 \%)$ & $+2.9 \%$ & 16.14 & $\begin{array}{c}-26 \% \text { to }-28 \% \text { of } 2005 \text { by } \\
2025\end{array}$ \\
\hline 3 & EU & $3,450(9.1 \%)$ & $-1.9 \%$ & 6.78 & $-40 \%$ of 1990 by 2030 \\
\hline 4 & India & $2,622(6.9 \%)$ & $+7.2 \%$ & 1.94 & No commitment to peak \\
\hline 5 & Russia & $1,748(4.6 \%)$ & $+3.6 \%$ & 12.14 & $\begin{array}{c}\text { None listed on UNFCCC } \\
\text { site }\end{array}$ \\
\hline \multirow[t]{2}{*}{6} & Japan & $1,200(3.2 \%)$ & $-1.7 \%$ & 10.4 & $-25 \%$ of 2005 by 2030 \\
\hline & Subtotal & $25,557(67.5 \%)$ & $+1.9 \%$ & & \\
\hline 7 & Iran & $728(1.9 \%)$ & $+4.8 \%$ & 8.87 & $\begin{array}{c}\text { None listed on UNFCCC } \\
\text { site }\end{array}$ \\
\hline 8 & S. Korea & $695(1.8 \%)$ & $+2.9 \%$ & 13.59 & $-37 \%$ from BAU by 2030 \\
\hline 9 & S. Arabia & $625(1.6 \%)$ & $-1.1 \%$ & 18.63 & No commitment to peak \\
\hline 10 & Canada & $594(1.6 \%)$ & $-0.1 \%$ & 16.08 & $-30 \%$ of 2005 by 2030 \\
\hline 11 & Indonesia & $557(1.5 \%)$ & $+4.8 \%$ & 2.09 & $\begin{array}{c}-29 \% \text { to }-41 \% \text { BAU by } \\
2030\end{array}$ \\
\hline 12 & Brazil & $500(1.3 \%)$ & $-1.3 \%$ & 2.37 & $-43 \%$ of 2000 by 2050 \\
\hline 13 & Mexico & $496(1.3 \%)$ & $-2.3 \%$ & 3.79 & $-50 \%$ of 2005 by 2030 \\
\hline 14 & S. Africa & $477(1.3 \%)$ & $+1.0 \%$ & 8.32 & $\begin{array}{c}398-614 \text { Gt by } 2025 \text { or } \\
2030\end{array}$ \\
\hline 15 & Turkey & $417(1.1 \%)$ & $+0.6 \%$ & 3.09 & $\begin{array}{l}\text { None listed on UNFCCC } \\
\text { site }\end{array}$ \\
\hline \multirow[t]{6}{*}{16} & Australia & $415(1.1 \%)$ & $+0.9 \%$ & 16.77 & $\begin{array}{c}-26 \% \text { to }-28 \% \text { of } 2005 \text { by } \\
2030\end{array}$ \\
\hline & Subtotal & $5,504(14.5 \%)$ & & & \\
\hline & Total -16 & $31,061(82 \%)$ & & & \\
\hline & A\&S (N.5) & $1,292(3.4 \%)$ & $+3.0 \%$ & & \\
\hline & All others & $5,534(14.6 \%)$ & & & \\
\hline & World & 37,887 & $+2.1 \%$ & 4.97 & \\
\hline
\end{tabular}

Notes: 1 The numbers and ranking in columns A to E are taken from European Commission, Joint Research Centre, Emissions Database for Global Atmospheric Research [EDGAR], 2019 Report (EC, 2019), Table 1 and elsewhere. These numbers are fossil-fuel $\left(E_{F F}\right)$ emissions only.

2 Although the EDGAR numbers for individual nations or regions represent only fossil-fuel $\left(E_{F F}\right)$ emissions, they may be regarded as the best measure for the discussion in this paper, since among all anthropogenic GHG emissions sources those from fossil-fuel use are the most amenable to regulatory and policy direction at the national level.

3 Column F: UNFCCC-NDC. BAU = business-as-usual scenario.

4 International aviation (594) and international shipping (698). These two plus the top 16 emitters (including EU-28) thus account for over $85 \%$ of total global emissions, leaving a mere $14.6 \%$ for all the remaining 142 countries together which are signatories to the Paris Agreement. 
Table 2 Projected increases/decreases in $\mathrm{CO}_{2}$ emissions (top 6) by 2030

\begin{tabular}{lcccc}
\hline Country & $\begin{array}{c}\text { A: 2018 MT } \\
\text { emissions (Table 1) }\end{array}$ & $\begin{array}{c}\text { B: expected 2030 } \\
\text { missions MT (INDCS) }\end{array}$ & C: INDC Paris Pledge & $\begin{array}{c}\text { D: Projected } \\
\text { change (MT) }\end{array}$ \\
\hline $\begin{array}{l}\text { China } \\
\text { India }\end{array}$ & 11,256 & 14,000 & Peaking around 2030 & $+2,750$ \\
Russia & 2,622 & 6,100 & $\begin{array}{c}\text { Reduce emissions } \\
\text { intensity }\end{array}$ & $+3,475$ \\
Japan & 1,748 & 2,175 & +18 to $+26 \%$ of 2016 & +425 \\
by 2030 & \\
EU-28 & 1,200 & 950 & $-25 \% 2005(1,277)$ & -250 \\
USA & 3,450 & 2,650 & $-40 \% 1990(4,409)$ & -800 \\
Totals & 5,275 & 3,700 & $-27 \% 1990(5,086)$ & $-1,575$ \\
Change & 25,550 & 29,575 & & $+16 \%$ \\
\hline
\end{tabular}

Notes: 1 Columns $A$ and $B$ : numbers rounded. Again, note that the numbers in column A are from EDGAR (as per Table 1) and are for $\mathrm{CO}_{2}$ only. Olivier and Peters (2018, Table B.1), provides $\mathrm{GtCO}_{2}$ eq numbers by country for 2017 , which include all greenhouse gases, and the numbers in that table are therefore higher. Both sets of numbers exclude LULUCF. See also IEA (2020).

2 Column D: Assumes that INDC pledge is fulfilled in most cases (UNFCCC, 2019b, 2019c).

3 China: Average annual national growth (EDGAR, EC, 2019) from 2010 $(9,170)$ to $2018(11,256)=261 \mathrm{Mt} /$ year $(\sim 2.6 \%$ annually $)$; China's projected growth rate for 2019 is $2.6 \%$ (Friedlingstein et al., 2019). Here we estimate an average annual growth rate for the period from 2018 to 2030 of $+2 \%$ annually (cf. CAT, 2019b).

4 India: Its INDC states that there is a commitment to almost quadruple its GDP in the 16 years between 2014 and 2030 [India, (2015), p.6], with a promise to reduce emissions intensity of GDP by $34 \%$ below 2005 levels by 2030 . In our calculation, we have multiplied the 2018 emissions by 3 ( $75 \%$ increase for the remaining 12 years: 7,866 ) and then applied a $34 \%$ reduction to the increase of 2030 over $2018(5,244 \times-34 \%=1,783)$, yielding an estimated 2030 emissions figure of $6,100 \mathrm{Mt}$.

5 Russia: CAT (2019c).

6 USA: The Paris Pledge was made in 2015 during the Obama administration. As of the time of writing, new policies under the Trump administration will result in higher emissions (CAT, 2019d) and the USA withdrew from the Paris Agreement on November 4, 2020, but the new Biden administration has promised to have the USA rejoin the Agreement as soon as it takes office.

\section{Avoiding $1.5^{\circ} \mathrm{C}$ and $2^{\circ} \mathrm{C}$ warming}

A number of considerations relating to the achievability of global warming targets are of vital importance. Fully half of all emissions for the period 1750-2011 occurred within the last 40 years (IPCC, 2014b), highlighting the most recent era as the source of the world's current climate change problems. However, as noted earlier, it is not only the recent GHG emissions that are driving climate change, but the total accumulation over more than a century. This is the first of at least three fundamental equity issues in climate change action, for it signals again the importance of the distinction between historic cumulative emissions and current ones (Frame et al., 2014). In 1990, the year often used in 
international negotiations as a baseline for emissions reductions targets, the historical share of emissions was as follows: USA (31\%), EU-28 (30\%), and Japan 7\%, for a total of $68 \%$ ['cumulative $\mathrm{CO}_{2}$ emissions by World Region' (Ritchie and Roser, 2020), interactive graphic]. At that time, China's share stood at $5.36 \%$ and India's at a mere $1.52 \%$.

It would therefore appear that the burden of any corrective actions applied specifically to the relative weighting on historic emissions would fall squarely on just those three nations and regions where significant emissions reduction commitments in the NDCs have already been registered and expected: the USA, the EU-28, and Japan. However, it is very difficult to foresee how any further major adjustments could be made to these three NDCs in order to address this equity issue [see Raupach et al. (2014), Pauw et al. (2019b) and especially Hof et al. (2017) on abatement costs for enhanced NDCs]. There are, of course, no enforcement mechanisms in the Paris Agreement (Karlsson-Vinkhuyzen et al., 2017).

The second equity issue is related to the truism that in earlier stages of modernisation all national economies have a higher level of energy-intensity and GHG emissions relative to GDP than they do when they later develop greater energy efficiency. This is why making progress in this area is a part of some of the developing-nations' initial NDCs under the Paris Agreement. Historical fairness demands that this be recognised as a legitimate contribution on their part to mitigation efforts. This is also why assistance from developed to developing nations has been stipulated in all stages in the UNFCCC processes (including clean development mechanisms, technology transfer, financial flows, and capacity building). But this unavoidable economic disadvantage can only be overcome slowly and doing so is expensive; consequently, this area is unlikely to be the source of any significant new commitments for emissions reductions.

The third equity issue also involves current emissions and is something that always has been explicitly recognised in agreements under the UNFCCC, namely, the marked differences around the world in per capita GHG emissions (Trinastic, 2015; Robiou du Pont et al., 2017; Ritchie, 2018). In Table 1, per capita emissions among just the top 6 emitters in 2018 ranged from a low of 1.9 tonnes (India) to a high of 16 tonnes (USA). In terms of historic emissions, per capita $\mathrm{CO}_{2}$ emissions in the baseline year 1990 were: USA, 20.14; Russian Federation, 16.12; EU-28, 9.34; Japan, 9.23; China, 2.06; and India, 0.70 [Olivier and Peters, (2018), Table A.2, all units in tonnes]. One thinks especially of the continent of Africa, having some of the lowest emissions (except for South Africa) and poorest peoples in the world, and facing some of the harshest impacts of global warming (Althor et al., 2016). There are no obvious or easy solutions to the inequities represented by large differences in per capita GHG emissions that are relevant to the campaign against climate change.

The present-day consequences of these inequities are to a large extent intractable. Looking forward to 2030, the Parties' NDCs will be caught tightly in a vise, with redistributional pressures from equity issues on the one side, and the possibility that there will be relatively small resources available from developed nations to respond to them, on the other (Pauw et al., 2019a). What this means is that future increases in GHG emissions from China, India, and many other developing nations must be expected and cannot be amended in the short-term, and that they are likely to outweigh substantially any new reductions made by developed nations. More specifically, no reasonably foreseeable set of additional contributions can come anywhere close to the Talanoa objective of reducing emissions by $50 \%$ from 2018 levels by 2030 . 
As a result, and given the NDCs submitted by these Parties and currently in place, passing the $1.5^{\circ} \mathrm{C}$ warming threshold for 2030 - possibly by a wide margin - seems unavoidable. Moreover, exceeding the $2^{\circ} \mathrm{C}$ warming threshold appears to be inevitable or at least very likely. Peters et al. (2015) comment: "It is clear from our analysis that the EU, US, and Chinese INDCs are not consistent with the $2^{\circ} \mathrm{C}$ goal ... [and] are more consistent with a temperature increase of $3^{\circ} \mathrm{C}$ with a $>66 \%$ chance" (see also Robiou du Pont and Meinshausen, 2018). The risk of overshooting $1.5^{\circ} \mathrm{C}$ puts the world on a trajectory to reach $+2^{\circ} \mathrm{C}$ perhaps sooner than 2050 . How serious would it be to pass the point at which a $2^{\circ} \mathrm{C}$ global temperature increase above pre-industrial levels occurs? Might a $+2^{\circ} \mathrm{C}$ global warming be the level at which humanity would be set on an unavoidable course for a catastrophic future? A scientific paper published by Steffen et al. (2018) begins as follows:

\begin{abstract}
"We explore the risk that self-reinforcing feedbacks could push the Earth system toward a planetary threshold that, if crossed, could prevent stabilization of the climate at intermediate temperature rises and cause continued warming on a 'Hothouse Earth' pathway even as human emissions are reduced [emphasis added]. Crossing the threshold would lead to a much higher global average temperature than any interglacial in the past 1.2 million years and to sea levels significantly higher than at any time in the Holocene."
\end{abstract}

According to these scientists (see also Lenton et al., 2019), passing the threshold of a $+2{ }^{\circ} \mathrm{C}$ global average temperature increase is likely to set in motion what they call 'tipping cascades', which are positive biogeophysical feedback loops (such as permafrost thawing, loss of sea ice, and release of frozen methane from oceans) that accentuate the trends in rising temperatures already occurring. Potential catastrophic effects following $+2^{\circ} \mathrm{C}$ include sea-level rise of 2-3 metres or more by 2100 , severe reductions in food output, extensive dieback of both boreal and tropical forests, and extreme heat [Steffen et al., (2018), Appendix; Mora et al., 2017]. But the even more serious problem is that, once at $+2^{\circ} \mathrm{C}$ the climate system may become locked into the 'Hothouse Earth' pathway, causing more temperature increases that will be irreversible, the effects from which will persist for millennia thereafter.

\title{
5 Paths forward
}

The amount of time elapsed so far in the overall UNFCCC process (1989-2019) has been 30 years. Another timeline that may be more relevant is to count the 25 years from 1990 to 2015, when the Paris Agreement came into being, because at the Paris meeting parties for all practical purposes gave up on attempting to set binding targets for national emissions reductions, which had been the focus of the Kyoto Protocol.

Pledges for specified reductions targets in the first commitment period of the Kyoto Protocol were made in 1997 only by a large group of countries in Europe along with Japan, the USA, and Canada (UNFCCC, 2008). But the USA never ratified the Protocol and Canada first agreed and then withdrew, essentially leaving only Europe and Japan, which together account for less than $15 \%$ of total global emissions. For Kyoto's second commitment period (2013-2020), only the EU plus Iceland, representing less than $10 \%$ of global emissions, have made a specific reduction pledge, that is, $20 \%$ below their 1990 levels. Spanning the course of some 70 international meetings held between 1989 and the present, apart from the EU-28, Japan, and Iceland, none of the other countries in the 
world, which taken together represent about $85 \%$ of global emissions, has ever to date made and then held to a specific numerical pledge for reduced emissions. Jackson et al. (2018) sum up as follows: "a quarter century after the United Nations Framework Convention on Climate Change, we remain far from its signature goal to "stabilize greenhouse gas concentrations in the atmosphere at a level that would prevent dangerous anthropogenic interference with the climate system"."

In the consensus views of climate scientists, as summarised above, there is already, as of 2020, a fair amount of confidence in three key propositions.

1 Without more decisive and timely action, passing the $+2{ }^{\circ} \mathrm{C}$ warming level will be unavoidable.

2 There is a serious risk that passing the $+2{ }^{\circ} \mathrm{C}$ threshold will lock in irreversible further warming regardless of emissions reductions undertaken thereafter.

3 Warming at $+2^{\circ} \mathrm{C}$ and above will inevitably result in catastrophic outcomes.

The Sword of Damocles - representing the possibility that the world may not avoid arriving at, or even overshooting, a $2^{\circ} \mathrm{C}$ warming scenario - hangs over all the participants. When all is said and done, it is entirely possible that both Kyoto's partial top-down approach and Paris's inclusive bottom-up one will ultimately fail.

\section{Impacts of policy inaction}

Climate change presents an exceeding difficult challenge for which no easy or clear solution presently exists (Grundmann, 2016). This is in part because delays, including century-long delays, are inherent in the very nature of this issue. The delay elements in climate change include the long residence time of GHGs; the lag between emissions and increased $\mathrm{CO}_{2}$ concentrations in the atmosphere; finding the limits of absorption for the ocean sinks; the slow but relentless pace in the depletion of the allowable carbon budget, calculated from year 1750 onwards; the postponing of the most obvious adverse impacts far into the future, when it will be impossible to avoid them; and, above all, the still-shrouded potential compound events or tipping points, when positive feedback loops might start to kick in, producing runaway escalation in further climate forcing [on the last point see Chapter 15, 'Potential Surprises', in the United States, Global Change Research Program, Climate Science Special Report (2017)].

The consequences of delaying policy actions needed to address the dilemmas inherent in these delays are shown in the $\mathrm{CO}_{2}$ mitigation curves in Figure 2.

At this point in time avoiding $+1.5^{\circ} \mathrm{C}$ is now probably unattainable. Although the annualised targets for emissions reductions are less severe for avoiding $2{ }^{\circ} \mathrm{C}$, they are still onerous ['mitigation curves for $2^{\circ} \mathrm{C}$ ' (Global Carbon Project, 2018)].

The majority of key conclusions in the IPCC reports are now made with high confidence or very high confidence, based on the underlying analytical models, supporting data, and many years of seeking consensus judgments. But how likely is it that their judgments will win the day in the court of world public opinion, sometime within the next 20 years or so? How likely is it that the majority of citizens will demand that their governments enact a binding, verifiable, and enforceable international treaty that is sufficiently robust to drive GHG emissions down to the net zero level by sometime 
between 2050 and 2080? It would be nice to be able to say that we know the answer to these questions with any level of confidence at all.

Figure 2 Results of delays in climate change action (see online version for colours)

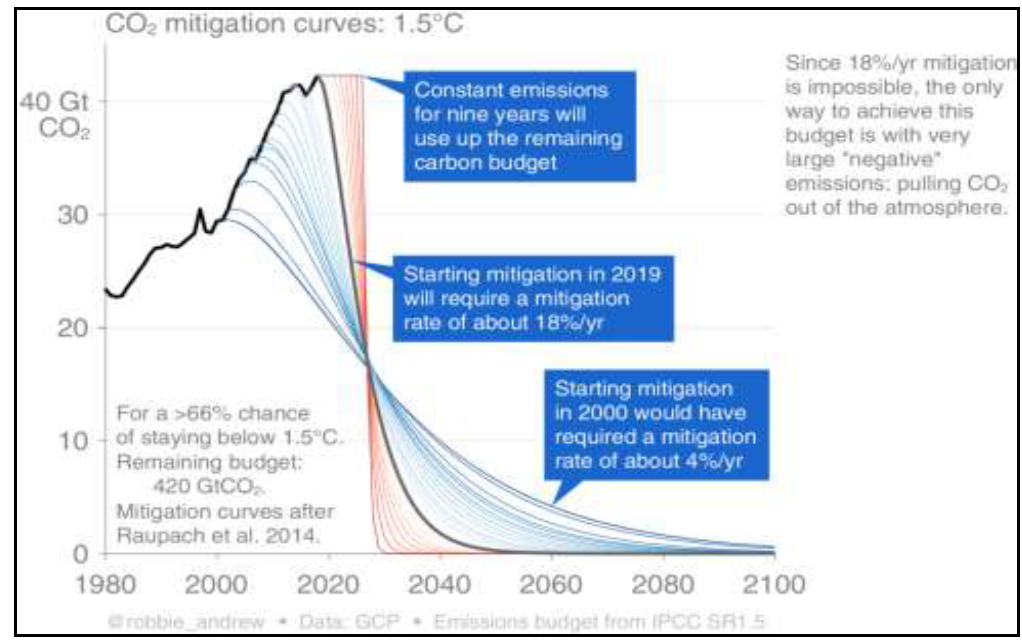

Source: Global Climate Project (2018)

\section{Implementing change for policy action}

A serious mismatch between the current international treaty and the most recent climate science was explicitly acknowledged in the most recent proceedings under the Paris Agreement, namely the Talanoa dialogue, which served as the first stocktaking of progress under the Agreement: "reports submitted to the Talanoa dialogue indicate that the aggregate efforts from existing NDCs fall well short of achieving the long-term goal of the Paris Agreement" (Talanoa, 2018a). The challenge was stated more explicitly in the 'Talanoa call for action', a joint statement by the Presidents of COP 23 and COP 24 [Talanoa, (2018b), p.1]:

\footnotetext{
"According to the science, global emissions continue to rise. This leaves a significant gap in the effort needed to limit global warming to well below 2 degrees Celsius above pre-industrial levels and to pursue efforts to limit the temperature increase to 1.5 degrees Celsius. The IPCC Special Report on 1.5 degrees highlights, among other things, the benefits of holding warming to below 1.5 degrees. It also concludes that to keep global warming within 1.5 degrees, global emissions need to be halved by 2030."
}

But the existing set of NDCs will not even come anywhere close to halving current emissions levels by 2030 (Peters et al., 2015; IPCC, 2018).

In the modern era humanity has faced certain types of major existential risks, such as two World Wars and the later threat of massive destruction and radioactive contamination from large-scale nuclear warfare. Today it is the SARS-COV-2 virus. But it has never faced a risk such as climate change, for at least two reasons. First, climate change very gradually 'loads' into the climate system a number of truly catastrophic impacts but defers their appearance into some distant future time, impacts that are not now evident 
and therefore do not seem to be of immediate relevance. Moreover, these projected impacts can only be given in the form of probabilistic estimates, so that it is possible - and perhaps even reasonable in the eyes of many - to believe that they might never come to pass. Second, this loading of likely future impacts is such that, given sufficient additional GHG emissions associated with human activity, the world will unwittingly cross a kind of invisible threshold, beyond which no subsequent mitigation efforts will be able to prevent those catastrophic impacts from occurring. These are the reasons why climate change represents an unprecedented challenge to the future of humanity.

Climate change is the type of problem which offers a supreme test of the existing framework of international environmental treaty law. It is an inescapable truth that to date the nations of the world have failed that test. To be sure, other experiences with seeking to use international law to deal with environmental issues - chemical, biological, and nuclear arms threats - have shown that very long timeframes can be involved in finding even imperfect solutions to them (see Section $\mathrm{C}$ in the supplementary information to this paper). But the well-hidden aspect of inevitability inherent in climate change presents a special challenge in this regard. In the climate change case, the science of climate forcing has compressed mercilessly the timeframe available to the nations of the world for effective action on climate change. This has resulted in a steadily collapsing interval between achieving an agreement among nations on GHG emissions reductions, on the one hand, and the window of opportunity for avoiding dangerous interference with the climate system, on the other.

Some of the most recent climate science journal articles present the consequences of this collapsing interval in the starkest terms. Lewis et al. (2019) remark that "none of the major emitters has made commitments [under the Paris Agreement] that are aligned with limiting warming to $2^{\circ} \mathrm{C}$ " and that current climate pledges "are estimated to result in a median global warming range of $2.6-3.1^{\circ} \mathrm{C}$ above pre-industrial levels", thus re-confirming an analysis first published in Peters et al. (2015). Jiang et al. (2018) state: “A mitigation pathway consistent with the Paris Agreement's 'well below $2{ }^{\circ} \mathrm{C}$ ' target requires halving gross $\mathrm{CO}_{2}$ emissions every decade from $\sim 40 \mathrm{GtCO}_{2}$ equivalent in 2020 to $\sim 5 \mathrm{GtCO}_{2}$ in 2050 (the "carbon law')." This is functionally equivalent to the proposition that the Paris 2015 goals have no chance of being met. And time to remedy the situation is perilously short (Figueres et al., 2017). That this type of requirement seems so utterly unrealistic, in the context of all the internationally-negotiated steps taken in the past 30 years, is perhaps the best indicator of the ongoing dilemma that the world now faces with respect to climate change.

The world requires greater focus on what can reasonably expected to happen, in terms of global emissions, over the next decade. In this paper we suggest that there is only one realistic scenario under which the world as a whole can realise the further emission reductions needed to avoid "dangerous anthropogenic interference with the climate system." And that is, for decarbonisation strategies to be widely adopted in all of the still developing economies, using massive subsidies from the developed world. We recognise the unprecedented global response to COVID-19 could create further opportunities for climate mitigation to be emphasised during the recovery period. We also recognise that geo engineering for climate change mitigation shows some promise; however, there is little doubt that any attempt to successfully incorporate geo engineering technologies within new international treaty negotiations on climate change would be at least as 
difficult as any of the steps undertaken so far (see the supplementary information paper for a discussion on this point).

New approaches along these lines must be forged. As of year 2018, 142 of the 185 countries which signed the Paris Agreement represented about $46 \%$ of the earth's human population of 7.6 billion, but (as shown in Table 1) accounted for only about $15 \%$ of its GHG emissions. Many of them are still poor and underdeveloped, and there is little doubt that they will need to grow their economies, and their energy usage, in the future (importantly, as will one of the top 6 emitters, India). Thus one key approach could relate to the pledge by 18 developed countries, made in 2015 , in the context of the negotiations leading up to the Paris Agreement, to direct very significant funding to less-developed economies in order to avert emissions rises there (UNFCCC, 2015c). This could be done by donating non-fossil-fuel energy technologies to them on a large scale. This approach, if adopted, would have the added advantage of stimulating the further development of the needed technologies, which Jiang et al. (2018) have called for in pointing to the situation of the developing world as a key factor in what they call the 'mitigation challenge' within the Paris Agreement. But five years on, this pledge has not been redeemed. Furthermore, only if this support is front-loaded is there a good chance this strategy might succeed (Leiss, 2019). It should be tried.

Appendices/Supplementary materials are available on request by emailing the corresponding author or can be obtained under https://doi.org/10.7910/dvn/2sui27.

\section{Acknowledgements}

We thank two reviewers for comments on an earlier version of the manuscript.

\section{References}

Althor, G. et al. (2016) Global Mismatch between Greenhouse Gas Emissions and the Burden of Climate Change, Scientific Reports, Vol. 6, p.20281, DOI: 10.1038/srep20281 [online] https://www.ncbi.nlm.nih.gov/pmc/articles/PMC4742864/pdf/srep20281.pdf (accessed 20 July 2020).

Bodansky, D. (2016) 'The legal character of the Paris Agreement', Review of European, Comparative and International Environmental Law, Vol. 25, No. 2, pp.142-150.

Canada (2017) Auditor General of Canada, Report of the Commissioner of Environment and Sustainable Development, Progress in Reducing Greenhouse Gases, Exhibit 1.5 [online] http://www.oag-bvg.gc.ca/internet/English/parl_cesd_201710_01_e_42489.html (accessed 20 July 2020).

Canada (2019) Environment Canada, 2019 National Inventory Report 1990-2017 [online] http://publications.gc.ca/collections/collection_2019/eccc/En81-4-1-2017-eng.pdf (accessed 20 July 2020).

Climate Action Tracker (CAT) (2019a) [online] https://climateactiontracker.org/countries/canada/ (accessed 20 July 2020).

Climate Action Tracker (CAT) (2019b) [online] https://climateactiontracker.org/countries/china/ (accessed 20 July 2020).

Climate Action Tracker (CAT) (2019c) [online] https://climateactiontracker.org/countries/russianfederation/ (accessed 20 July 2020). 
Climate Action Tracker (CAT) (2019d) [online] https://climateactiontracker.org/countries/usa/ (accessed 20 July 2020).

Climate and Clean Air Coalition (CCAC) (2018) Addressing Black Carbon Emission Inventories, May [online] file:///C:/Users/Administrator/Downloads/2018_Science-Update-Black-CarbonBriefing_CCAC.pdf (accessed 12 December 2020).

Doelle, M. (2016) 'The Paris Agreement: historic breakthrough or high stakes experiment?', Climate Law, Vol. 6, Nos. 1-2, pp.1-20.

Doelle, M. (2017) 'The Paris Climate Agreement: assessment of strengths and weaknesses', in Klein, D. et al. (Eds.): The Paris Agreement on Climate Change: Analysis and Commentary, Oxford University Press, Oxford, UK.

Doelle, M. (2019) 'The heart of the Paris Rulebook: communicating NDCs and accounting for their implementation', Climate Law, Vol. 9, p.3 [online] https://ssrn.com/abstract=3332792.

European Commission (EC) (2019) Fossil CO2 Emissions of All World Countries, Joint Research Centre [online] https://ec.europa.eu/jrc/en/publication/eur-scientific-and-technical-researchreports/fossil-co2-and-ghg-emissions-all-world-countries-0 (accessed 9 September 2020).

Fawzy, S., Osman, A.I., Doran, J. et al. (2020) 'Strategies for mitigation of climate change: a review', Environ. Chem. Lett. [online] https://doi.org/10.1007/s10311-020-01059-w (accessed 8 September 2020).

Figueres, C. et al. (2017) 'Three years to safeguard our climate', Nature, Vol. 546, pp.593-595 [online] https://doi.org/10.1038/546593a.

Forster, P.M., Maycock, A.C., McKenna, C.M. et al. (2020) 'Latest climate models confirm need for urgent mitigation', Nat. Clim. Chang., Vol. 10, pp.7-10 [online] https://doi.org/10.1038/ s41558-019-0660-0 (accessed 8 September 2020).

Frame, D.J., Macey, A.H. and Allen, M.R. (2014) 'Cumulative emissions and climate policy', Nature Geoscience, Vol. 7, pp.692-693.

Friedlingstein, P. et al. (2019) 'Global Carbon Budget 2019', Earth Syst. Sci. Data, Vol. 11, pp.1783-1838 [online] https://www.earth-syst-sci-data.net/11/1783/2019/ (accessed 9 September 2020).

Fuss, S. et al. (2014) 'Betting on negative emissions', Nature Climate Change, Vol. 4, No. 2014, pp.850-853.

Global Carbon Project (2018) Global Carbon Budget [online] https://www.globalcarbonproject. org/carbonbudget/18/files/GCP_CarbonBudget_2018.pdf (accessed 20 July 2020).

Global Climate Project (2018) Figures from the Global Carbon Budget 2018 (Robbie Andrew) [online] http://folk.uio.no/roberan/GCB2018.shtml (accessed 20 July 2020).

Goodwin, P. et al. (2018a) 'Pathways to $1.5^{\circ} \mathrm{C}$ and $2{ }^{\circ} \mathrm{C}$ warming based on observational and geological constraints', Nature Geoscience, Vol. 11, No. 2, pp.102-107.

Goodwin, P. et al. (2018b) 'Adjusting mitigation pathways to stabilize climate at $1.5^{\circ} \mathrm{C}$ and $2.0^{\circ} \mathrm{C}$ rise in global temperatures to year 2300', Earth's Future, Vol. 6, pp.601-615 [online] https://doi.org/10.1002/2017EF000732 (accessed 20 July 2020).

Grundmann, R. (2016) 'Climate change as a wicked social problem', Nature Geoscience, Vol. 9, No. 8 , pp.562-563.

Hansen, J. et al. (2007) 'Dangerous human-made interference with climate: a GISS modelE study', Atmos. Chem. Phys., Vol. 7, No. 2007, pp.2287-2312.

Hausfather, Z. et al. (2020) 'Evaluating the performance of past climate projection models', Geophysical Research Letters, Vol. 47, No. 1 [online] https://doi.org/10.1029/2019GL085378 (accessed 08 September 2020).

Hof, A.E. et al. (2017) 'Global and regional abatement costs of nationally determined contributions (NDCs) and of enhanced action to levels well below $2{ }^{\circ} \mathrm{C}$ and $1.5^{\circ} \mathrm{C}$ ', Environmental Science \& Policy, Vol. 71, pp.30-40 [online] https://doi.org/10.1016/j.envsci.2017.02.008 (accessed 8 September 2020). 
Houghton, R.A. and Nassikas, A.A. (2017) 'Global and regional fluxes of carbon from land use and land use cover change 1850-2015', Global Biogeochemical Cycles, Vol. 31, pp.456-472 [online] https://agupubs.onlinelibrary.wiley.com/doi/epdf/10.1002/2016GB005546 (accessed 20 July 2020).

Hsu, A. et al. (2019) 'A research roadmap for quantifying non-state and subnational climate mitigation action', Nature Climate Change, Vol. 9, pp.11-17 [online] https://doi.org/10.1038/ s41558-018-0338-z.

India (2015) India's Intended Nationally Determined Contribution [online] https://www4.unfecc. int/sites/ndcstaging/PublishedDocuments/India\%20First/INDIA\%20INDC\%20TO\%20UNFC CC.pdf (accessed 20 July 2020).

Intergovernmental Panel on Climate Change (IPCC) (2001) Working Group I: The Scientific Basis, Third Assessment Report [online] https://www.ipcc.ch/report/ar3/wg1/ (accessed 20 July 2020).

Intergovernmental Panel on Climate Change (IPCC) (2014a) Climate Change 2014: Mitigation of Climate Change, Working Group III Contribution to the Fifth Assessment Report of the Intergovernmental Panel on Climate Change [online] http://www.ipcc.ch/report/ar5/wg3/ (accessed 20 July 2020).

Intergovernmental Panel on Climate Change (IPCC) (2014b) Climate Change 2014, Synthesis Report [online] https://ar5-syr.ipcc.ch/ipcc/ipcc/resources/pdf/IPCC_SynthesisReport.pdf (accessed 20 July 2020).

Intergovernmental Panel on Climate Change (IPCC) (2018) Global Warming of $1.5^{\circ} \mathrm{C}$, Special Report (SR-15) [online] https://www.ipcc.ch/sr15/ (accessed 20 July 2020).

International Energy Agency (IEA) (2020) Key World Energy Statistics 2020, August [online] https://www.iea.org/reports/key-world-energy-statistics-2020 (accessed 08 September 2020).

Jackson, R.B. et al. (2017) 'Warning signs for stabilizing global $\mathrm{CO}_{2}$ emissions', Environ. Res. Lett., Vol. 12, p.110202 [online] http://iopscience.iop.org/article/10.1088/1748-9326/ aa9662/pdf (accessed 20 July 2020).

Jackson, R.B. et al. (2018) 'Global energy growth is outpacing decarbonization', Environ. Res. Lett., Vol. 13, p.120401 [online] https://iopscience.iop.org/article/10.1088/1748-9326/ aaf303/pdf (accessed 20 July 2020).

Jackson, R.B. et al. (2019) 'Persistent fossil fuel growth threatens the Paris Agreement and planetary health', Environ. Res. Lett., Vol. 14, p.121001 [online] https://doi.org/10.1088/17489326/ab57b3 (accessed 20 July 2020).

Jiang, X. et al. (2018) 'Global rules mask the mitigation challenge facing developing countries', Earth's Future, Vol. 7 [online] https://agupubs.onlinelibrary.wiley.com/doi/epdf/10.1029/ 2018EF001078 (accessed 20 July 2020).

Karlsson-Vinkhuyzen, S.I. et al. (2017) 'Entry into force and then? The Paris Agreement and state accountability', Climate Policy, Vol. 18, No. 5, pp.593-599 [online] https://www.tandfonline.com/doi/full/10.1080/14693062.2017.1331904 (accessed 20 July 2020).

Leiss, W. (2019) 'A global decarbonisation bond', Environmental Research Letters, Vol. 14, No. 9 [online] https://iopscience.iop.org/article/10.1088/1748-9326/ab396f/meta (accessed 20 July 2020).

Lenton, T.M. et al. (2019) 'Climate tipping points - too risky to bet against', Nature, Vol. 575, pp.592-595 [online] https://doi.org:10.1038/d41586-019-03595-0 (accessed 8 September 2020).

Lewis, S.L. et al. (2019) 'Assessing contributions of major emitters' Paris-era decisions to future temperature extremes', Geophysical Research Letters, pp.3936-3943 [online] https://agupubs. onlinelibrary.wiley.com/doi/full/10.1029/2018GL081608 (accessed 20 July 2020). 
Mathews, D. et al. (2018) 'Focus on cumulative emissions, global carbon budgets, and the implications for carbon mitigation targets', Environmental Research Letters, Vol. 13, p.010201 [online] https://iopscience.iop.org/journal/1748-9326/page/Cumulative\%20emission s (accessed 20 July 2020).

Mengis, N. et al. (2018) $1.5^{\circ} \mathrm{C}$ Carbon Budget Dependent on Carbon Cycle Uncertainty and Future Non-CO forcing, Scientific Reports, Vol. 8, Article No. 5831, p.8 [online] https://www.nature. com/articles/s41598-018-24241-1 (accessed 20 July 2020).

Mitchell, D. et al. (2018) 'The Paris Agreement: understanding the physical and social challenges for a warming world of $1.5^{\circ} \mathrm{C}$ above pre-industrial levels', Philosophical Transactions of the Royal Society A, 13 May, Vol. 376, No. 2119 [online] https://royalsocietypublishing.org/toc/ rsta/376/2119 (accessed 20 July 2020).

Mora, C. et al. (2017) 'Global risk of deadly heat', Nature Climate Change, Vol. 7, pp.501-506.

National Academies Press (NAP) (2001) Climate Change Science: An Analysis of Some Key Questions, USA [online] https://www.nap.edu/download/10139 (accessed 20 July 2020)

National Oceanographic and Atmospheric Administration (NOAA), USA (2019) [online] https://esrl.noaa.gov/gmd/aggi/aggi.html (accessed 20 July 2020).

Olivier, J.G.J. (2011) Long-Term Trends in Global $\mathrm{CO}_{2}$ Emissions: 2011 Report, PBL Netherlands Environment Assessment Agency [online] https://www.pbl.nl/sites/default/files/downloads/ C02_Mondiaal_webdef_19sept.pdf (accessed 20 July 2020).

Olivier, J.G.J. and Peters, J.J.H.W. (2018) Trends in Global $\mathrm{CO}_{2}$ and Total Greenhouse Gas Emissions: 2018 Report, PBL Netherlands Environment Assessment Agency [online] https://www.pbl.nl/en/publications/trends-in-global-co2-and-total-greenhouse-gas-emissions2018-report (accessed 20 July 2020).

Olivier, J.G.J. and Peters, J.J.H.W. (2019) Trends in Global $\mathrm{CO}_{2}$ and Total Greenhouse Gas Emissions: 2019 Report, PBL Netherlands Environment Assessment Agency [online] https://www.pbl.nl/sites/default/files/downloads/pbl-2020-trends-in-global-co2-andtotalgreenhouse- gas-emissions-2019-report_4068.pdf (accessed 20 July 2020).

Pauw, P., Mbeva, K. and van Asselt, H. (2019b) 'Subtle differentiation of countries' responsibilities under the Paris Agreement', Palgrave Commun., Vol. 5, p.86 [online] https://doi.org/10.1057/s41599- 019-0298-6 (accessed 8 September 2020).

Pauw, W.P., Castro, P., Pickering, J. and Bhasin, S. (2019a) 'Conditional nationally determined contributions in the Paris Agreement: foothold for equity or Achilles heel?', Climate Policy, DOI: 10.1080/14693062.2019.1635874.

Peters, G.P. et al. (2015) 'Measuring a fair and ambitious climate agreement using cumulative emissions', Environ. Res. Lett., Vol. 10 p.105004 [online] https://iopscience.iop.org/article/ $10.1088 / 1748-9326 / 10 / 10 / 105004 / p d f$ (accessed 20 July 2020).

Peters, G.P. et al. (2019) 'Carbon dioxide emissions continue to grow amidst slowly emerging climate policies', Nature Climate Change, Vol. 10, pp.3-6 [online] https://doi.org/10.1038/ s41558-019-0659-6 (accessed 20 July 2020).

Raupach, M.R. et al. (2014) 'Sharing a quota on cumulative carbon emissions', Nature Climate Change, and Supplementary Information, Vol. 4, No. 2014, pp.873-879.

Ritchie, H. (2018) Global Inequalities in $\mathrm{CO}_{2}$ Emissions, Our World in Data, Blog Post, 4 December [online] https://ourworldindata.org/global-inequalities-co2-consumption (accessed 20 July 2020).

Ritchie, H. and Roser, M. (2020) $\mathrm{CO}_{2}$ and Greenhouse Gas Emissions: Annual $\mathrm{CO}_{2}$ Emissions by World Region, Our World in Data [online] https://ourworldindata.org/co2-and-othergreenhousegas- emissions (accessed 20 July 2020).

Robiou du Pont, Y. and Meinshausen, M. (2018) 'Warming assessment of the bottom-up Paris Agreement emissions pledges', Nature Communications, Vol. 9, p.4810 [online] https://www. nature.com/articles/s41467-018-07223-9.pdf (accessed 20 July 2020).

Robiou du Pont, Y. et al. (2017) 'Equitable mitigation to achieve the Paris Agreement goals', Nature Climate Change, Vol. 7, No. 2017, pp.38-43. 
Rocha, M. et al. (2015) Historical Responsibility for Climate Change - From Countries Emissions to Contribution to Temperature Increase [online] https://www.climateanalytics.org/media/ historical_responsibility_report_nov_2015.pdf(accessed 20 July 2020).

Saxifrage, B. (2019) Canada's Climate Gap Widens Yet Again, Canada's National Observer, 30 January [online] https://www.nationalobserver.com/2019/01/30/analysis/canadasclimategap-widens-yet-again (accessed 20 July 2020).

Smith, D.M. et al. (2018) 'Predicted chance that global warming will temporarily exceed $1.5^{\circ} \mathrm{C}$ ', Geophysical Research Letters, Vol. 45, No. 11, pp.895-11903 [online] https://doi.org/ 10.1029/2018GL079362 (accessed 20 July 2020).

Steffen, W. et al. (2018) 'Trajectories of the Earth system in the anthropocene, Appendix: supporting information: holocene variability and anthropocene rates of change', Proceedings of the National Academy of Sciences, 14 August, Vol. 115, No. 33, pp.8252-8259 [online] https://www.pnas.org/content/115/33/8252 (accessed 20 July 2020).

Talanoa (2018a) Synthesis of the Preparatory Phase, 19 November [online] https://img1. wsimg.com/blobby/go/9fc76f74-a749-4eec-9a06-5907e013dbc9/downloads/1cu4u95lo 238771.pdf (accessed 20 July 2020).

Talanoa (2018b) Presidents of COP23 and COP24, Talanoa Call for Action [online] https://unfccc.int/sites/default/files/resource/Talanoa\%20Call\%20for\%20Action.pdf (accessed 20 July 2020).

Toronto Conference (1988) The Changing Atmosphere, Conference Statement [online] $\mathrm{http} / / / \mathrm{cmosarchives.ca/History/ChangingAtmosphere1988e.pdf} \mathrm{(accessed} 20$ July 2020).

Trinastic, J. (2015) Equity or Inertia: How Emissions Sharing Philosophies Shape Climate Policy Success, Nature Blog, 29 October [online] https://www.nature.com/scitable/blog/eyesonenvironment/emission_pledges_from_us_eu (accessed 20 July 2020).

United Nations Framework Convention on Climate Change (UNFCCC) (1992) [online] http://unfccc.int/files/essential_background/background_publications_htmlpdf/application/pdf/ conveng.pdf (accessed 20 July 2020)

United Nations Framework Convention on Climate Change (UNFCCC) (2008) Kyoto Protocol Reference Manual [online] https://unfccc.int/resource/docs/publications/08_unfccc_kp_ref_ manual.pdf (accessed 20 July 2020).

United Nations Framework Convention on Climate Change (UNFCCC) (2012) Doha Amendment to the Kyoto Protocol, Article 1: Amendment [online] https://unfecc.int/files/kyoto_protocol/ application/pdf/kp_doha_amendment_english.pdf (accessed 20 July 2020).

United Nations Framework Convention on Climate Change (UNFCCC) (2015a) Paris Agreement [online] http://unfccc.int/paris_agreement/items/9485.php (accessed 20 July 2020).

United Nations Framework Convention on Climate Change (UNFCCC) (2015b) Synthesis Report on the Aggregate Effect of the Intended Nationally Determined Contributions, FCCC/CP/2015/7 [online] https://unfccc.int/sites/default/files/resource/docs/2015/cop21/eng/ 07.pdf (accessed 20 July 2020).

United Nations Framework Convention on Climate Change (UNFCCC) (2015c) External Statement/07 Sep, 2015, 18 Donor States Determined to Commit 100 Billions for Climate Finance [online] https://unfccc.int/news/18-industrial-states-release-climate-financestatement (accessed 30 October 2020).

United Nations Framework Convention on Climate Change (UNFCCC) (2019a) Kyoto Protocol - Targets for the First Commitment Period [online] http://unfccc.int/kyoto_protocol/ items/2830.php (accessed 20 July 2020).

United Nations Framework Convention on Climate Change (UNFCCC) (2019b) Inventory Data [online] https://di.unfccc.int/detailed_data_by_party (accessed 20 July 2020).

United Nations Framework Convention on Climate Change (UNFCCC) (2019c) NDC Registry (Interim) [online] https://www4.unfccc.int/sites/NDCStaging/Pages/All.aspx (accessed 20 July 2020). 
United States, Global Change Research Program, Climate Science Special Report (2017) [online] https://science2017.globalchange.gov/.

US Department of Energy, Carbon Dioxide Information Analysis Center (CDIAC) (2019) [online] https://cdiac.ess-dive.lbl.gov/ftp/ndp030/global.1751_2014.ems (accessed 20 July 2020).

$\mathrm{Xu}, \mathrm{Y}$. and Ramanathan, V. (2017) 'Well below $2{ }^{\circ} \mathrm{C}$ : mitigation strategies for avoiding dangerous to catastrophic climate changes', Proc. Natl Acad. Sci., Vol. 114, pp.10315-10323 [online] https://www.pnas.org/content/114/39/10315 (accessed 20 July 2020).

$\mathrm{Xu}$, Y. et al. (2018) 'Global warming will happen faster than we think', Nature, 6 December, Vol. 564, pp.31-33 [online] https://www.nature.com/articles/d41586-018-07586-5 (accessed 20 July 2020). 